\title{
DETERMINAN TINGKAT PENGETAHUAN TENTANG RISIKO PEMAKAIAN HEADSET DENGAN SIKAP PENGGUNAAN HEADSET PADA MAHASISWA
}

Ida Listiana* , M. Hasan' Wida Rosmayati'

STIKes Widya Dharma Husada Tangerang, Jl. Pajajaran No. 1 Pamulang, Tangerang Selatan 15417, Indonesia

\begin{tabular}{|c|c|}
\hline ARTICLE INFORMATION & $A B S T R A C T$ \\
\hline $\begin{array}{l}\text { *Corresponding Author } \\
\text { Ida Listiana } \\
\text { E-mail: idalistiana8@gmail.com }\end{array}$ & \multirow{2}{*}{$\begin{array}{l}\text { Headset refers to a pair of small loudspeakers that are worn on or around } \\
\text { the head above the user's ear. World Health Organization (WHO) stated in } \\
2019 \text { that nearly } 50 \% \text { or } 1.1 \text { billion adolescents and young adults (12 to } 35 \\
\text { years old) are at risk of hearing loss due to loud and long exposure to } \\
\text { sound, including music they listen to through personal audio devices and } \\
\text { the } 2018 \text { WHO projection shows that if no action is taken, there will be } 630 \\
\text { million people living with hearing loss by } 2030 \text { and this number will } \\
\text { continue to grow or } 1 \text { in } 10 \text { will experience hearing loss. The objective of } \\
\text { this research is to determine a correlation between the students } \\
\text { understanding of the headset usage risk and their attitudes of using headset } \\
\text { at semester IV nursing students of STIKes Widya Dharma Husada } \\
\text { Tangerang. The result of this research based on the data collected from the } \\
\text { students showed that } 21 \text { students with well understanding of the headset } \\
\text { usage risk have shown positive attitudes (32.3\%). Meanwhile, } 44 \text { (67,7\%) } \\
\text { students with well understanding of the headset usage risk have shown } \\
\text { negative attitudes. The result of the statistical calculation found that (p- } \\
\text { value=0,421, } \alpha: \text {, 05). Therefore, it can conclude that there is no } \\
\text { correlation between the students understanding of the headset usage risk } \\
\text { and their attitudes of using headset. The suggestion based on this research } \\
\text { is students should contribute by raising awareness about hearing loss and } \\
\text { how to prevent it. }\end{array}$} \\
\hline $\begin{array}{c}\text { Keywords: } \\
\text { - Headset usage risk } \\
\text { - } \quad \text { understanding } \\
\text { - Attitudes }\end{array}$ & \\
\hline $\begin{aligned} & \text { Kata Kunci: } \\
& \text { - } \\
& \text { - } \text { Risiko pemaketahuan } \\
& \text { - } \text { Sikap }\end{aligned}$ & $\begin{array}{l}\text { Headset adalah merupakan sepasang benda pengeras suara yang kecil yang } \\
\text { diletakkan pada kedua telinga. Menurut World Health Organization (WHO) } \\
\text { tahun } 2019 \text { terdapat data yang menunjukkan } 50 \% \text { orang berusia } 12-35 \\
\text { tahun Atau sebanyak } 1,1 \text { miliar anak muda berisiko tinggi mengalami } \\
\text { gangguan pendengaran akibat terpapar suara keras dan berkepanjangan } \\
\text { (termasuk musik yang didengarkan melalui perangkat audio pribadi dan } \\
\text { proyeksi ). WHO tahun } 2018 \text { menunjukkan jika tidak ada tindakan yang } \\
\text { diambil, akan ada } 630 \text { juta orang yang hidup dengan gangguan pendengaran } \\
\text { pada tahun } 2030 \text { dan jumlah ini akan terus bertambah atau } 1 \text { dari } 10 \text { orang } \\
\text { akan mengalami gangguan pendengaran. Tujuan dari penelitian ini adalah } \\
\text { untuk mengetahui hubungan antara tingkat pengetahuan tentang risiko } \\
\text { penggunaan headphone dengan sikap penggunaan headphone pada } \\
\text { Mahasiswa semester IV jurusan Keperawatan di STIKes Widya Dharma } \\
\text { Husada Tangerang. Metode penelitian ini adalah analisis deskriptif dan } \\
\text { menggunakan metode cross-sectional dengan alat survei kuesioner. Besar } \\
\text { sampel adalah } 73 \text { siswa dengan menggunakan teknik non probability } \\
\text { sampling dan metode quota sampling.. Hasil penelitian diperoleh bahwa } 21 \\
\text { responden dengan tingkat pengetahuan baik tentang risiko pemakaian } \\
\text { headset dengan sikap positif (32,3\%), sedangkan } 44 \text { (67,7\%) memiliki } \\
\text { tingkat pengetahuan baik dengan sikap penggunaan headset yang negatif. } \\
\text { Hasil uji statistik diperoleh nilai ( nilai p-=0,421, a: 0,05). Maka dapat } \\
\text { disimpulkan bahwa tidak ada hubungan antar tingkat pengetahuan tentang } \\
\text { risiko pemakaian headset dengan sikap penggunaan headset. Saran dari } \\
\text { hasil penelitian ini Mahasiswa harus berkontribusi dengan meningkatkan } \\
\text { kesadaran tentang gangguan pendengaran dan bagaimana mencegahnya. }\end{array}$ \\
\hline
\end{tabular}




\section{PENDAHULUAN}

Headset adalah kombinasi dari headset dan microphone Mikrofon adalah sepasang speaker kecil yang ditempatkan di kedua telinga, digunakan untuk mendengarkan suara dan mengobrol dengan jebakan komunikasi atau komputer. Diperkirakan 50\% dari mereka mendengarkan musik melalui headset, dan intensitas kebisingan telinga bagian dalam lebih besar daripada intensitas kebisingan musik yang didengar tanpa headset dengan volume yang sama, karena sumber suara lebih dekat.

Menurut WHO (2019) ada data sebanyak $50 \%$ orang berusia $12-35$ tahun atau sebanyak 1,1 miliar anak muda berisiko kehilangan pendengaran karena terpapar suara keras dan berkepanjangan (termasuk musik yang sering mereka dengarkan melalui perangkat audio pribadi). Data tersebut menemukan bahwa lebih dari 5\% penduduk dunia, yaitu 466 juta orang mengalami gangguan pendengaran, 432 juta $(93 \%)$ orang dewasa adalah anakanak, dan 34 juta (7\%) anak-anak yang kualitas hidupnya terpengaruh.

Proyeksi WHO (2018) baru-baru ini menunjukan jika tidak ada tindakan yang diambil, 630 juta orang akan menderita gangguan pendengaran pada tahun 2030. Jumlah ini diperkirakan akan tumbuh menjadi angka yang bertambah meningkat dari 900 juta pada tahun 2050 atau setidaknya akan ada 1 dari 10 orang akan mengalami gangguan pendengaran.

Menurut artikel Tempo.co (2017) Di Indonesia, jumlah pengguna ponsel aktif semakin meningkat.Lembaga riset pemasaran digital E-marketer memperkirakan jumlah pengguna ponsel aktif di Indonesia akan melebihi 100 juta pada tahun 2018. Dengan jumlah sebesar itu, Indonesia menjadi pengguna ponsel aktif terbesar keempat di dunia setelah China, India, dan Amerika Serikat. Banyaknya pengguna ponsel di Indonesia yang perlu diwaspadai karena erat kaitannya dengan gangguan pendengaran. Perilaku mendengarkan yang tidak aman (seperti mendengarkan musik dalam waktu lama melalui headset untuk waktu yang lama) dapat menyebabkan gangguan pendengaran akibat kebisingan (GPAB), yang mungkin bersifat sementara atau permanen.

Berdasarkan data Riskesdas pada tahun 2013 didapatkan prevelensi. Gangguan pendengaran antara usia 5-14 dan 15-25 tahun adalah $0,8 \%$, dan prevalensi ketulian pada kelompok usia yang sama adalah 0,04\%. Data tersebut menunjukkan bahwa gangguan pendengaran masih menjadi masalah kesehatan masyarakat. Program Pencegahan Tuli Indonesia berfokus pada penyakit yang dapat dicegah, salah 
satunya gangguan pendengaran akibat kebisingan (GPAB).

Berdasarkan fenomena yang di temukan maka di buatlah Bagaimana pertanyaan yang dikemukakan dalam penelitian ini "determinan tingkat pengetahuan tentang risiko pemakaian headset dengan sikap penggunaan headset pada Mahasiswa Keperawatan semester IV di STIKes Widya Dharma Husada Tangerang".

\section{METODE}

Jenis penelitian yang digunakan adalah analisis deskriptif dengan metode cross-sectional, yaitu studi tentang dinamika hubungan antara faktor dan pengaruh melalui metode observasi atau pengumpulan data satu kali (point-time approach ). Amati objek penelitian hanya sekali, dan ukur keadaan karakter atau variabel objek selama inspeksi (Gahayu, 2015).

Lokasi penelitian dilakukan pada mahasiswa semester IV jurusan keperawatan di STIKes Widya Dharma Husada Tangerang. Penelitian ini dilakukan mulai April 2020 hingga Mei 2020

Populasi dalam Studi ini adalah Mahasiswa semester IV jurusan Keperawatan STIKes Widya Dharma Husada Tangerang berjumlah 290 Mahasiswa
Penelitian ini menggunakan kombinasi teknik non-probability sampling dan teknik quota sampling. Dengan menggunakan rumus Arikunto untuk menghitung 20\% dari populasi diperoleh sampel sebanyak 73 responden.

\section{HASIL}

\section{Analisa Univariat}

Tabel 1. Distribusi Frekuensi Berdasarkan Usia

\begin{tabular}{lll} 
Usia & Frekuensi & $\begin{array}{l}\text { Presentase } \\
(\%)\end{array}$ \\
18 & 3 & 4,1 \\
19 & 34 & 46,6 \\
20 & 32 & 43,8 \\
21 & 4 & 5,5 \\
\hline Total & 73 & 100
\end{tabular}

Sumber: data primer 2020

Distribusi frekuensi responden menurut usia di antara 73 responden menunjukkan bahwa hampir tidak ada responden yang berusia di bawah 18 tahun sebanyak $3(4,1 \%)$, dan hampir separuh responden berusia di bawah 19 tahun. Sebanyak 34 responden $(46,6 \%)$, hampir separuh responden memiliki sebanyak $32(43,8 \%)$ saat berusia 20 tahun, dan sebanyak 4 responden berusia 21 tahun (terhitung 5,5\%). 
Tabel 2. Distribusi Frekuensi Berdasarkan Jenis Kelamin Mahasiswa

Jenis kelamin Frekuensi Presentase

Laki-Laki $\quad 8$

Perempuan 65

Total

73

11

89

Sumber: data primer 2020

Distribusi frekuensi 73 responden berdasarkan jenis kelamin menunjukkan bahwa sebagian kecil responden berjenis kelamin laki-laki yaitu sebanyak 8 (11\%), sedangkan sebagian besar responden adalah perempuan sebanyak $65(89 \%) . \%)$.

Tabel 3. Distribusi Frekuensi Berdasarkan Pekerjaan Orang Tua

\begin{tabular}{lll}
\hline $\begin{array}{l}\text { Pekerjaan Orang } \\
\text { Tua }\end{array}$ & Frekuensi & $\begin{array}{l}\text { Presentase } \\
(\%)\end{array}$ \\
PNS & 9 & 12,3 \\
Guru & 4 & 5,5 \\
Anggota & 3 & 4,1 \\
TNI/POLISI & & \\
Karyawan & 23 & 31,5 \\
Swasta & 28 & 38,4 \\
Wiraswasta & 28 & 8,2 \\
Buruh & 6 & 100
\end{tabular}

Sumber: data primer 2020

Distribusi frekuensi responden berdasarkan situasi kerja orang tua responden sebanyak 73 responden, ditemukan sebagian kecil PNS sebanyak 9 orang ( $12,3 \%)$, dan sebagian kecil guru berjumlah 4 orang. orang. (5,5\%), hampir tidak ada yang berstatus sebagai Anggota TNI / POLRI sebanyak 3 (4,1\%), dimana hampir separuhnya adalah pegawai swasta, sebanyak 23 (31,5\%), dan hampir separuhnya adalah wiraswasta sebanyak
$28((38,4 \%)$ dan sebanyak 6 dalam kelompok kecil pekerja $(8,2 \%)$.

Tabel 4. Distribusi Frekuensi Berdasarkan Tingkat Pengetahuan tentang Risiko Pemakaian Headset

\begin{tabular}{lll}
$\begin{array}{l}\text { Tingkat } \\
\begin{array}{l}\text { Pengetahuan } \\
\text { tentang Risiko }\end{array}\end{array}$ & Frekuensi & $\begin{array}{l}\text { Presentase } \\
(\%)\end{array}$ \\
$\begin{array}{l}\text { Pemakaian } \\
\text { Headset }\end{array}$ & & \\
Baik & 65 & 89 \\
Kurang & 8 & 11 \\
\hline Total & 73 & 100
\end{tabular}

Sumber: data primer 2020

Distribusi frekuensi responden berdasarkan pengetahuan tentang risiko pemakaian headset dari sebanyak 73 responden didapatkan hasil sebagian besar responden berpengetahuan Baik sebanyak 65 orang (89\%), sebagian kecil responden memilik pengetahuan yang Kurang tentang risiko pemakaian headset sebanyak 8 orang $(11 \%)$.

Tabel 5. Distribusi Frekuensi Sikap Penggunaan Headset

Sikap Frekuensi Presentase

Penggunaan

Headset

$\begin{array}{lll}\text { Positif } & 22 & 30,1\end{array}$

$\begin{array}{lll}\text { Negatif } & 51 & 69,9\end{array}$

$\begin{array}{lll}\text { Total } & 73 & 100\end{array}$

Sumber : data primer 2020

Diperoleh hasil distribusi frekuensi responden berdasarkan sikap penggunaan headset dari sebanyak 73 responden dengan hasil hampir setengah responden memiliki sikap yang Positif sebanyak 22 
orang $(30,1 \%)$, lebih dari setengah Negatif terhadap penggunaan headset responden mempunyai sikap yang sebesar 51 orang $(69,9 \%)$.

\section{Analisa Bivariat}

Tabel 6 Analisa Hubungan Tingkat Pengetahuan tentang Risiko Pemakaian Headset dengan Sikap Penggunaan Headset

\begin{tabular}{llllllll}
\hline \multirow{2}{*}{$\begin{array}{l}\text { Pengetahuan tentang Risiko } \\
\text { Pemakaian Headset }\end{array}$} & \multicolumn{7}{c}{ Sikap Penggunaan Headset } \\
\cline { 2 - 9 } & \multicolumn{2}{l}{ Positif } & \multicolumn{2}{c}{ Negatif } & \multicolumn{2}{c}{ Total } & \multicolumn{1}{c}{ P- } \\
\cline { 2 - 9 } Baik & $\mathrm{N}$ & $\%$ & $\mathrm{~N}$ & $\%$ & $\mathrm{~N}$ & $\%$ & \\
Kurang & 21 & 32,3 & 44 & 67,7 & 65 & 100 & \multirow{2}{*}{0,421} \\
\hline Total & 1 & 12,5 & 7 & 87,5 & 8 & 100 & \\
\hline
\end{tabular}

Sumber :data primer 2020

Tabel 6. diperoleh hasil hampir setengah 65 responden yang memiliki pengetahuan baik yang mempunyai sikap penggunaan headset yang positif sebanyak 21 responden $(32,3 \%)$, lebih dari setengah yang memiliki pengetahuan baik dengan sikap penggunaan headset yang negatif sebanyak 44 responden $(67,7 \%)$, sedangkan sebagian kecil dari 8 responden yang mempunyai pengetahuan kurang dengan sikap penggunaan positif sebanyak 1 responden (12,5) dan sebagian besar yang mempunyai pengetahuan kurang dengan sikap penggunaan headset yang negatif sebanyak 7 orang $(87,5 \%)$.

Data penelitian ini tidak memenuhi syarat uji chi-square karena ada salah satu yang kurang dari 5 sehingga dilakukan uji alternatifnya yaitu Fisher's Exact Test. Dari hasil uji statistik analisa didapatkan adanya hubungan tingkat pengetahuan mahasiswa tentang risiko pemakaian headset dengan sikap mahasiswa tentang penggunaan headset didapatkan nilai $\mathrm{p}$-value $=0.421$ $>\alpha=0.05$, dengan demikian disimpulkan bahwa $\mathrm{H} \alpha$ ditolak artinya tidak terdapat hubungan antar tingkat pengetahuan tentang risiko pemakaian headset dengan sikap penggunaan headset pada Mahasiswa/i Keperawatan semester IV STIKes Widya Dharma Husada Tangerang.

\section{PEMBAHASAN}

\section{Analisa Univariat}

\section{Usia}

Distribusi frekuensi responden berdasarkan usia didapatkan yaitu hampir setengah responden berusia 19 tahun sebanyak 34 responden (46,6\%). Menurut Ilma (2016) ada beberapa faktor yang dapat mempengaruhi pengetahuan seseorang 
salah satunya usia mempengaruhi daya tangkap dan pola pikir seseorang, bertambahnya usia akan semakin berkembang pola pikir dan daya tangkap seseorang sehingga pengetahuan yang diperolehnya akan semakin membaik. Hal ini tidak sama dengan penelitian Zaima Dzatul Ilma pada tahun 2016 dimana mayoritas responden berusia 16 tahun yaitu sebanyak $60,7 \%$ dari total responden hal ini disebabkan karena perbedaan sampel yang digunakan.

\section{Jenis Kelamin}

Distribusi frekuensi responden berdasarkan jenis kelamin didapatkan hasil sebagian besar responden berjenis kelamin perempuan sebanyak 65 responden (89\%). Berdasarkan data Riskesdas pada tahun 2013 didapatkan prevelensi, gangguan pendengaran berdasarkan jenis kelamin yaitu perempuan $2,8 \%$ dan laki-laki $2,4 \%$ serta prevelensi ketulian pada perempuan 0,10\% dan laki-laki 0,09\%.

Hal ini sama dengan penelitian Zaima Dzatul Ilma tahun 2016 dimana responden terbanyak adalah perempuan dengan persentasi $65,1 \%$ tetapi penelitian ini tidak sama dengan yang dilakukan oleh Upik Rahmi., dkk tahun 2015 dimana responden terbanyaknya adalah laki-laki dengan persentasi 51,9\%.

\section{Pekerjaan Orang Tua}

Distribusi frekuensi responden berdasarkan pekerjaan orang tua didapatkan hasil yaitu hampir setengah orang tua responden bekerja sebagai Wiraswasta sebanyak 28 responden $(38,4)$. Menurut Ilma (2016) Seseorang yang bekerja akan berinteraksi dengan orang lain sehingga mendapatkan berbagai macam informasi yang dapat menambah pengetahauan serta pengalaman seseorang dan status ekonomi seseorang juga menentukan tersedianya suatu fasilitas yang diperlukan untuk kegiatan tertentu, sehingga status sosial ekonomi akan memengaruhi pengetahuan seseorang.

\section{Pengetahuan tentang Risiko}

\section{Pemakaian Headset}

Distribusi frekuensi responden berdasarkan tingkat pengetahuan tentang risiko pemakaian headset didapatkan hasil sebagian besar sebanyak 65 responden (89\%) memiliki skor pengetahuan yang baik. Terdapat faktor-faktor yang mempengaruhi pengetahuan yaitu usia, pendidikan, informasi atau media massa, lingkungan, sosail dan ekonomi (Ilma, 2016). Cukupnya pengetahuan mengenai risiko dari pemakaian headset khususnya gangguan pendengaran dapat disebabkan oleh beberapa faktor 
tersebut. Untuk meningkatkan pengetahuan diperlukan informasi dari pendidikan formal dan informal sehingga berpengaruh terhadap pengetahuan, wawasan dan pendapat yang luas.

Hal ini sama dengan penelitian Zaima tahun 2016 dimana sebanyak 96,1\% memiliki skor pengetahuan yang baik dan hanya 3,9\% yang memiliki skor pengetahuan yang buruk tetapi penelitian ini tidak sama dengan penelitian Alvin Laoh., dkk tahun 2015 Diantaranya, 63,3\% responden tidak mengetahui risiko seringnya menggunakan headset, sedangkan $36,7 \%$ responden mengetahui risiko seringnya menggunakan headset.

\section{Sikap Penggunaan Headset}

Distribusi frekuensi responden berdasarkan sikap penggunaan headset didapatkan hasil lebih dari setengahnya responden memiliki sikap negatif terhadap penggunaan headset, dan sebanyak 51 responden (69,9\%). Menurut Notoatmodjo (2012), sikap bukanlah perilaku atau aktivitas, melainkan kerentanan perilaku.

Hal ini sama dengan penelitian Zaima tahun 2016 Diantaranya, sebanyak $86,9 \%$ memiliki sikap buruk dan hanya $13,1 \%$ yang memiliki sikap baik.Namun, penelitian ini berbeda dengan penelitian tahun 2016 oleh Tiara dkk. Pada survei terakhir tahun 2016, 80,9\% memiliki sikap baik, $17,1 \%$ orang memiliki sikap yang cukup baik, dan $2 \%$ responden memiliki sikap yang buruk terhadap penggunaan headset

\section{Analisa Bivariat}

Analisa hubungan tingkat pengetahuan tentang risiko pemakaian headset dengan sikap penggunaan headset pada Mahasiswa/i Keperawatan semester IV di STIKes Widya Dharma Husada Tangerang dengan 73 respoden diperoleh hasil lebih dari setengah yang memiliki pengetahuan baik dengan sikap penggunaan headset yang negatif sebanyak 44 responden $(67,7 \%)$.

Data dalam penelitian ini tidak memenuhi persyaratan uji chi-square karena jumlahnya kurang dari 5, sehingga dilakukan uji lain yaitu uji eksak Fisher. Hasil analisis statistik hubungan tingkat pengetahuan mahasiswa tentang risiko penggunaan headset dan sikap mahasiswa terhadap penggunaan headset, $\mathrm{p}$-value $=$ $0,421>\alpha=0,05$, sehingga dapat disimpulkan bahwa $\mathrm{H} \alpha$ ditolak, Artinya bahwa pada semester IV mahasiswa jurusan keperawatan STIKes Widya Dharma Husada Tangerang tidak ada 
hubungan antara tingkat pengetahuan tentang risiko penggunaan headset dengan sikap penggunaan headset.

Menurut penelitian yang dilakukan oleh Upik, dkk tahun 2016 Jika headset tidak digunakan dengan benar, gangguan pendengaran di usia muda dapat berdampak serius pada pengguna headset. Penggunaan headset yang berlebihan, mendengarkan musik atau bermain game dalam waktu lama tanpa mengetahui waktu mungkin menjadi salah satu penyebab tuli permanen. (yankes.kemkes.go.id)

Informasi atau media massa yang merupakan faktor pendukung bagi seseorang untuk memperoleh pengetahuan dan informasi tentang risiko penggunaan headset (Ilma, 2016). Menurut penelitian Sunaryo dalam Chandra (2017), faktor-faktor yang mempengaruhi pembentukan dan perubahan sikap adalah faktor eksternal . Faktor eksternal tersebut juga dapat digunakan melalui alat perantara lainnya (seperti alat komunikasi dan media massa, baik elektronik maupun non-elektronik ), yang berdampak besar pada pembentukan opini dan kepercayaan seseorang.

Faktor lingkungan mempengaruhi proses penginputan pengetahuan ke dalam individu di lingkungan tersebut (Ilma,
2016). Menurut penelitian Upik et al., Pada tahun 2016, lingkungan sekitar dapat menjadi salah satu faktor yang mempengaruhi pertemanan dan lingkungan sekitarnya. Jika sudah terbiasa dengan lingkungan yang mengajarkan bagaimana cara menggunakan headset secara bijak, maka diharapkan hal ini berdampak positif pada pengetahuan tentang resiko menggunakan headset.

Hal ini tidak sejalan dengan penelitian Tiara et al. Pada tahun 2016 ditemukan proporsi siswa SMA di Kota Padang yang menggunakan headphone sebesar 83,6\%, dan ditemukan siswa memiliki pengetahuan dan sikap yang baik terhadap penggunaan headphone. Masing-masing menyumbang persentase (93, 4\%) dan (80,9\%). Pergerakan siswa yang menggunakan headphone cukup baik dengan persentase $(66,3 \%)$. Hasil penelitian menunjukkan bahwa sebagian besar siswa SMA Negeri Kota Padang telah menggunakan earphone, siswa tersebut memiliki pengethuan yang baik tentang efek earphone dan pencegahannya. Para siswa juga memiliki sikap yang baik dalam menggunakan earphone dan bekerja dengan baik saat menggunakan earphone. 


\section{KESIMPULAN}

Diperoleh bahwa 21 responden dengan tingkat pengetahuan baik tentang risiko pemakaian headset dengan sikap positif $(32,3 \%)$, sedangkan $44(67,7 \%)$ memiliki tingkat pengetahuan baik dengan sikap penggunaan headset yang negatif. Hasil uji statistik diperoleh nilai ( nilai $\mathrm{p}-=0,421, \alpha: 0,05)$. Maka dapat disimpulkan bahwa tidak ada hubungan antar tingkat pengetahuan tentang risiko pemakaian headset dengan sikap penggunaan headset. Saran dari hasil penelitian ini Mahasiswa harus berkontribusi dengan meningkatkan kesadaran tentang gangguan pendengaran dan bagaimana mencegahnya

\section{DAFTAR PUSTAKA}

Candra, I Wayan et al. Dasar ilmiah psikologi dan praktik keperawatan Jiwa. Yogyakarta: ANDI; 2017.

Dharma, Kelana Kusuma. Metodologi Penelitian Keperawatan: Panduan Melaksanakan dan Menerapkan Hasil Penelitian. Jakarta: Trans InfoMedia; 2018.

Ditjen Yankes. Sayangi telinga anda dengan mengurangi penggunaan headset secara berlebihan. 2019; Diakses $11 \quad$ Februari 2020 Available at: http://yankes.kemkes.go.id/readsayangi-telinga-penggunaanheadset-secara-berlebihan6775.html.
Gahayu, Sri Asih. Metodologi Penelitian Kesehatan Masyarakat. Yogyakarta: Deepublish; 2015.

Ilma, Zaima Dzatul. Pengaruh Pengetahuan dan Sikap Siswa SMA Terhadap Perilaku Penggunaan Peranti Dengar di SMAN $X$ Tangerang Selatan [Tesis]. Jakarta: Fakultas Ilmu kesehatan UIN Syarif Hidayatullah; 2016.

Kemenkes RI. Riset Kesehatan Dasar (Rikesdas) 2013. Jakarta : Kementrian kesehatan RI; 2013.

Kemenkes RI. Telinga sehat investasi masa depan. 2018; Diakses 16 Juli 2020 Available at: https://cantik.tempo.co/read/86052 9/sering-pakai-headset-aturvolume-dandurasinya/full\&view $=$ ok.

Kemenkes RI. Telinga sehat investasi masa depan. 2018; Diakses 16 Juli 2020 Available at: https://cantik.tempo.co/read/86052 9/sering-pakai-headset-aturvolume-dandurasinya/full\&view $=$ ok.

Laoh, Alvin et al. Hubungan penggunaan headset terhadap fungsi pendengaran pada mahasiswa angkatan 2012 fakultas Kedokteran Universitas Sam ratulangi. [Jurnal Kedokteran Komunitas dan Tropik] 2015; [Diakses 26 Januari 2020]. Available at: https://ejournal.unsrat.ac.id/index. php/JKKT/article/view/9102

Notoatmodjo, Soekidjo. Promosi Kesehatan dan Perilaku Kesehatan. Jakarta: Rineka Cipta; 2012. 
Rahmi, Upik et al. Gambaran Pengetahuan Siswa Kelas X dan XI tentang Penggunaan Earphone di SMA Pasundan di Kota Bandung [Jurnal Pendidikan Keperawatan Indonesia]. 2016; [Diakses 26 Januari 2020]. Available at: https://ejournal.upi.edu/index.php/ JPKI/article/view/4742

Tempo. Sering pakai headset, atur volume dan durasinya. 2017; Diakses 16 Juli 2020 Available at: https://cantik.tempo.co/read/86052 9/sering-pakai-headset-aturvolume-dandurasinya/full\&view=ok.

WHO. standard aims to prevent hearing loss among 1.1 billion young people. 2019; Diakses 11 Januari
2020 Available at:

https://www.who.int/newsroom/detail/12-02-2019-new-whoitu-standard-aims-to-preventhearing-loss-among-1.1-billionyoung-people.

WHO. Prevention of blindness and deafness. 2018; Diakses 12 Januari 2020 Available at: https://www.who.int/pbd/deafness/ estimates/en/.

Zain, Tiara Rahma et al. Gambaran perilaku remaja terhadap penggunaan earphone pada siswa SMA Negeri kota Padang. [Jurnal Kesehatan Andalas]. 2016;. [Diakses 06 February 2020]. at: http://jurnal.fk.unand.ac.id/index.p hp/jka/article/view/610 